\title{
HISTORIA DE LAS MATEMÁTICAS EN LA EDUCACIÓN MATEMÁTICA, UNA RUTA DE INVESTIGACIÓN, CREATIVIDAD Y DIVERSIDAD CULTURAL
}

\author{
Ligia Arantes Sad ${ }^{1}$ \\ ligia.sad@ifes.edu.br \\ Claudia A. C. de Araujo Lorenzoni ${ }^{1}$ \\ claudia.araujo@ifes.edu.br \\ ${ }^{1}$ Instituto Federal do Espírito Santo, Campus Vitória (Ifes-Vitória), Brasil
}

Recibido: 08/12/2019 Aceptado: 06/02/2020

\section{Resumen}

El texto discute el potencial y las contribuciones de la Historia de las Matemáticas en las prácticas de enseñanza de la Educación Matemática, ilustrada por dos episodios específicos de la práctica pedagógica de los autores. Toma como notas teóricas estudios como los de Ferreira, D'Ambrosio, Barbin, Jankivist y Vianna sobre los argumentos, implicaciones y sugerencias dirigidas al uso didáctico de la historia de las matemáticas. Los fundamentos de los autores se basan en un diálogo con la etnomatemática, entendiendo así las matemáticas escolares o las matemáticas, vistas en una forma occidental dominante, como una entre otras posibilidades de hacer y pensar matemáticamente. A lo largo del texto, la historia se destaca como un subsidio para la creación, tanto individual como colectiva, de explicaciones, relaciones de significados, objetos y significados que no se constituyeron hasta entonces. La creatividad, desde la perspectiva de Karwowski, Jankovska y Szwajkowski, y la investigación, en la línea de Ponte, se presentan como elementos relevantes en el proceso de enseñanza para estimular en cada estudiante una relación de construcción y apropiación del conocimiento matemático escolar de manera participativa. , interrogador y productor de nuevos conocimientos. Como resultado, señalamos: ser capaces de unir teorías e ideas científicas al analizar el potencial y las contribuciones de la Historia de las Matemáticas en las prácticas de enseñanza de la enseñanza de las matemáticas en la escuela, involucrando investigación y creatividad en metodologías y contextos híbridos de diferentes culturas.

Palabras clave: Historia de las matemáticas. Educación matemática escolar. Juegos indígenas tradicionales. Investigación y creatividad. 


\title{
HISTORY OF MATHEMATICS IN MATHEMATICAL EDUCATION, A ROUTE OF RESEARCH, CREATIVITY AND CULTURAL DIVERSITY
}

\begin{abstract}
The text discusses the potential and contributions of the History of Mathematics in teaching practices in Mathematical Education, illustrated by two specific episodes of the authors' pedagogical practice. It takes as theoretical notes studies like those of Ferreira, D'Ambrosio, Barbin, Jankivist and Vianna about the arguments, implications and suggestions directed to the didactic use of the history of mathematics. The authors' foundations are based on a dialogue with Ethnomathematics, thus understanding school mathematics or mathematics - seen in a dominant Western way - as one among other possibilities of doing and thinking mathematically. Throughout the text, history stands out as a subsidy for the creation, both individual and collective, of explanations, relations of meanings, objects and meanings that were not constituted until then. Creativity, from the perspective of Karwowski, Jankovska and Szwajkowski, and research, in the Ponte line, are presented as relevant elements in the teaching process in order to stimulate in each student a relationship of construction and appropriation of school mathematical knowledge in a participatory way, questioner and producer of new knowledge. As a result we point out - being able to unite theories and scientific ideas when analyzing potentialities and contributions of the History of Mathematics in teaching practices of school Mathematics teaching, involving research and creativity in hybrid methodologies and contexts of different cultures.
\end{abstract}

Keywords: History of Mathematics. School mathematical education. Traditional indigenous games. Research and creativity.

\section{HISTÓRIA DA MATEMÁTICA NA EDUCAÇÃO MATEMÁTICA, UMA VIA DE INVESTIGAÇÃO, CRIATIVIDADE E DIVERSIDADE CULTURAL}

\begin{abstract}
Resumo
O texto discute potencialidades e contribuições da História da Matemática em práticas docentes da Educação Matemática, ilustradas por dois episódios específicos da prática pedagógica das autoras. Toma como apontamentos teóricos estudos como os de Ferreira, D’Ambrosio, Barbin, Jankivist e Vianna acerca dos argumentos, implicações e sugestões direcionadas ao uso didático da história da matemática. Os fundamentos das autoras são alicerçados em diálogo com a Etnomatemática, entendendo, assim, a matemática ou a matemática escolar - vista de modo ocidental dominante - como uma entre outras possibilidades do fazer e pensar matematicamente. Ao longo do texto, destaca-se a história como subsídio para criação, tanto individual quanto coletiva, de explicações, relações de significados, objetos e sentidos que não estavam até então constituídos. A criatividade, na perspectiva de Karwowski, Jankovska e Szwajkowski, e a investigação, na linha de Ponte, são apresentadas como elementos relevantes no processo de ensino a fim de estimular em cada estudante uma relação de construção e apropriação do conhecimento matemático escolar de
\end{abstract}


forma participativa, questionadora e produtora de novos conhecimentos. Como resultado apontamos - poder unir teorias e ideias científicas ao analisar potencialidades e contribuições da História da Matemática em práticas docentes do ensino da Matemática escolar, envolvendo a investigação e a criatividade em metodologias híbridas e contextos de diferentes culturas.

Palavras-chave: História da Matemática. Educação matemática escolar. Jogos tradicionais indígenas. Investigação e criatividade.

\section{Introdução}

Ao longo dos anos de vivência acadêmica, na interdinâmica entre os campos de conhecimento da Educação Matemática e da História da Matemática, vários pesquisadores têm explorado as potencialidades e contribuições da História da Matemática no sentido de se tornar mais presente e poder fomentar uma matemática mais humanizada nas práticas docentes da Educação Matemática (Ferreira, 1998; D’Ambrosio, 2001; Barbin, 2006; Guillemette, 2015; Rogers e Pope, 2019). É nesse sentido que temos por objetivo central trazer à discussão compreensões sobre as potencialidades e contribuições da História da Matemática em práticas docentes da Educação Matemática.

Localmente, em Vitória-ES, também tem ocorrido, por décadas, uma busca desafiadora em nossas práticas enquanto educadoras na Educação Básica e na Educação Superior, mediante algumas estratégias e situações criadas para atuação nessa interface ou interdinâmica. Não podemos esquecer as influências curriculares que têm indicado, desde os PCN - Parâmetros Curriculares Nacionais (Brasil, 1998) até as atuais BNCC - Bases Nacionais Comuns Curriculares (Brasil, 2018), uma articulação bem vinda das ciências com a esfera social e cultural, que pode ser interpretada e carregada de sentido e significado mediante os relacionamentos com a história da matemática. Contudo, esses documentos oficiais normativos não provêm indicações de meios pedagógicos que, na prática docente, possam potencializar a comunidade escolar e acadêmica no trabalho com a presente diversidade cultural. Por um lado, que eles permitam mitigar a opressão e desigualdade social como fatores de desumanização das ciências de modo geral e, por outro, valorizar a condução de relações interculturais que respeitam e prezam valores defendidos em comunidades tradicionais como fontes de produção de novos significados, conhecimentos e criatividades. 
É pertinente comentar que consideramos o termo 'tradicional' como polissêmico, embora possa ser pensado com significado sintetizado de conjunto de traços culturais, passado e preservado de geração a geração, como princípios identitários. (Diegues; Arruda, 2001). Contudo, como as sociedades estão sempre em movimento de transformação, não é pertinente que se veja qualquer tipologização de "tradição" como algo estático e retrógrado, uma vez que a adjetivação de tradicional é lida, muitas vezes, com significados de uma antropologia ocidental. Enquanto que, "um dos critérios mais importantes para a definição de culturas ou populações tradicionais, além do modo de vida, é, sem dúvida, o reconhecer-se como pertencente àquele grupo social particular. Esse critério remete à questão fundamental da identidade" (Diegues; Arruda, 2001, p. 26, grifo dos autores). Acrescentamos ainda que tal critério se relaciona diretamente com o que aquele grupo cultural determina como ontologicamente próprio. Importante adicionar que não vemos como posições antagônicas o "tradicional" e o "novo", mesmo porque estamos constantemente nos valendo de aspectos tradicionais e históricos para a criação do novo. Burke (2005), ao comentar sobre a provocação que a tradição trouxe à historicidade, discute a produção de novas tradições, ao serem reinventadas em ações coletivas.

O entendimento na perspectiva de olhar as possibilidades da atuação, na prática educacional do professor que lida com a história da matemática como aliada ao ensino de matemática, tem levado a estudos como os de Jankvist (2009) sobre os argumentos para uso da história e categorização dos "porquês" e "como" utilizá-la. Ainda no final do século XX, Vianna (1995) discutiu algumas implicações e sugestões direcionadas ao uso didático da história da matemática, entre as quais destacamos a história como subsídio para criação, tanto individual quanto coletiva, de explicações, relações de significados, objetos e sentidos que não estavam até então constituídos.

Com esses apontamentos teóricos e caracterizações sobre o lugar de onde estamos a elaborar as narrativas e considerações analíticas, adotamos no restante do texto uma composição que, primeiramente, agrega de modo sintetizado compreensões a respeito de criatividade e investigação para, em sequência, articular com dois episódios específicos da nossa prática pedagógica local. Descrevemos as metodologias integradas aos episódios, discutindo-as como potentes vias de integração e produção de conhecimentos históricos, bem 
como de desenvolvimento do fazer matemático na educação escolar. Os caminhos a serem seguidos com a história da matemática e a matemática são ao mesmo tempo alicerçados em diálogo com a Etnomatemática, entendendo a matemática - vista de modo ocidental dominante - como uma entre outras possibilidades do fazer e pensar matematicamente.

\section{Compreensões e caracterizações sobre criatividade e investigação como metodologia}

A escolha de procedimentos metodológicos no ensino da matemática que fazemos ao trabalhar com determinada turma, depende de vários fatores, mas de forma predominante podemos buscar por sugestões dinâmicas que façam uso ou permitam incluir relacionamentos com a história da matemática. São preferenciais, procedimentos como de investigação, experimentos, atividades práticas, jogos e brincadeiras, dependendo da turma no que tange à

idade, nível de escolaridade e situações emergentes do contexto cultural. Isso porque queremos que os estudantes saiam de uma posição de "espectadores para se posicionarem como criadores ativos, não na perspectiva de serem cientistas ou técnicos, mas numa posição em que participem, compreendam e questionem o próprio conhecimento matemático escolar." (Mendes, 2009, p.109).

Antecedente a esse posicionamento, em geral, há uma "vontade consciente" do aprendiz para engajar-se nas ações que, segundo Vygotski (1995), é influenciada pela sensação interna de afeto, pelo ambiente social e cultural. De acordo com essa perspectiva, temos a defesa do papel fundamental desempenhado pela interação social na produção de significado durante o processo de ensino e aprendizagem. "O ponto crucial é que a sala de aula é um espaço simbólico. É um espaço que transmite valores culturais, científicos, estéticos, éticos e outros historicamente constituídos". (Radford, 2011, p. 325). Mas, como afirma Bishop (2008), valores educacionais estão impregnados da cultura das sociedades e valores de estudantes específicos vêm de seus contextos sociais específicos.

A exploração de determinado objeto ou situação histórica de certo modo envolve investigação, mas que tipo de investigação? Conforme Ponte (2003), temos uma gama variada de apropriações, desde simples buscas por informações utilizando pesquisa na Internet, até investigações no caso de situações mais abertas, sem definições precisas. Mas, a investigação matemática, que discutimos como procedimento metodológico possível para abordagens 
históricas em meio ao ensino de matemática, envolve as três fases apresentadas por Ponte, Brocardo e Oliveira (2009), quais sejam: “(i) introdução da tarefa, em que o professor faz a proposta à turma, oralmente ou por escrito, (ii) realização da investigação, individualmente, aos pares, em pequenos grupos ou com toda a turma, e (iii) discussão dos resultados [...]”.

No caso específico da investigação que se relaciona à história da matemática, temos alguns aspectos a comentar. $\mathrm{Na}$ fase (i), há inicialmente um diálogo a respeito da atividade de investigação, seguida de convite para ajudarem a pensar e levantar possíveis objetos matemáticos ou que foram construídos em contextos históricos, bem como situações caracterizadas por problemas mais abertos, antes mesmo de lançar propostas. Quanto à fase (ii), é importante que o professor fique atento à necessidade de orientar e levantar discussões críticas, não somente quanto às fontes utilizadas, para não haver escolhas muito deficitárias e até mesmo desânimos, mas, de modo específico, sobre o teor do que foi encontrado e as contribuições no sentido de justificações às possíveis conjecturas matemáticas. Já na última fase de discussão, os alunos além de relatar oralmente o que realizaram, por vezes são solicitados a cooperar na confecção de materiais, exposições e/ou relatórios.

Outro destaque que merece análises epistemológicas mais aprofundadas é a respeito do desenvolvimento de notadas dimensões que levam à criatividade. Uma capacidade bastante estudada cientificamente, mas que continua a não ter um modelo consensual, segundo Gerlovina (2011). A partir das leituras teóricas e de observações práticas, estamos considerando criatividade de acordo com Karwowski, Jankovska e Szwajkowski (2017) relacionada a um modelo de imaginação criativa - definida como a capacidade de criação expressiva e de imagens complexas; originalidade - capacidade de criar coisas únicas (novas); e de transformação. Aqui apenas explicitamos alguns aspectos que podem estar a contribuir a uma imaginação criativa no decorrer das atividades interdisciplinares envolvendo matemática, lembrando que ao longo da história da matemática existem vários exemplos de expoentes criativos, como os que podem ser observados na historiografia de criação dos jogos que abordaremos em um dos episódios da prática local. 


\section{Epidódio 1 - Povos tradicionais, jogos e matemática}

$\mathrm{Na}$ contemporaneidade, entre as formas culturais históricas de matematizar, manifestas por quase todos os grupos culturais, consideramos processos ou estratégias basilares como contar, medir, ordenar, classificar, desenhar, jogar e inferir, conforme perspectivas próximas assinaladas por Zaslavsky (1989), Bishop (1999) e D’Ambrosio (2001). Do entrelaçamento dessas atividades básicas provém todo o arcabouço dos saberes matemáticos historicamente constituídos em seus processos diferenciados de transformação cultural. Especificamente, situa-se o espaço de discussão deste presente artigo nessa confluência da formação histórica de um fazer matemático ensejado por jogos culturais tradicionais entre povos indígenas, aldeados há centenas de anos no Espírito Santo. Nesse sentido, o episódio aqui narrado apresenta resultados parciais de uma pesquisa mais ampla, em andamento junto aos Tupinikim e Guarani em Aracruz, no Espírito Santo, Brasil ${ }^{1}$, que envolve o contexto histórico dos povos, a educação matemática escolar indígena e não indígena e as transformações possíveis mediadas pelo diálogo intercultural, além de prezar pela criatividade em ações conjuntas, com a produção de novos significados e conhecimentos.

No País, é comum o termo "tupiniquim" ser usado no sentido de "nacional", "brasileiro". Todavia, o emprego do termo com esse sentido pode ofuscar a história e a existência desse povo habitante do Brasil desde antes da chegada dos colonizadores portugueses, que se autodenomina "Tupinikim", com "k" como explica Silva (2016). Em Terras Indígenas (TI) situadas no município de Aracruz, ao Norte do Estado do Espírito Santo, os Tupinikim, juntamente com os Guarani, vivem aldeados numa área de 18212,3314 hectares de extensão, segundo a Fundação Nacional do Índio - Funai (Brasil, 2013). O censo de 2010 (Brasil, 2013) contabilizou 3.005 indivíduos habitando a região, sendo a maioria Tupinikim. Em 2019, o número de indígenas nas TI do Estado passou para 4.052 (Brasil, 2019) .

Os Tupinikim, os Guarani e, de um modo geral, os povos indígenas têm produzido e transmitido, ao longo de sua história, saberes que são próprios à sua condição material, social, política, religiosa, etc. determinados por uma racionalidade que lhes é específica. Em meio ao trabalho sócio-histórico organizado e controlado no interior de cada grupo social desenvolvese uma maneira particular de produção de conhecimento. Em relação a populações indígenas é

\footnotetext{
1 Jogos e brincadeiras indígenas numa perspectiva etnomatemática. Brasil (Ifes Edital 04/2019; Ifes/CNPq, Editais 02 e 04/2019; Fundação de Amparo à Pesquisa e Inovação do Espírito Santo - Fapes - Edital 21-2018)
} 
pertinente a observação de Nascimento (2004, p. 88), "a percepção da totalidade que a vivência de uma doutrina de semelhança propicia ao índio permite que tudo aquilo que faz parte de seu habitat seja muito mais do que aparência objetiva de ser”.

Em Lorenzoni (2014) são apresentados grafismos da cestaria dos Guarani e os significados atribuídos por eles, paralelamente a ideias que poderiam ser chamadas de matemáticas. Mostra-se que o sentido matemático de cada grafismo não está desassociado do seu significado cultural. Além do que, em sociedades tradicionais os processos de comunicação de noções e saberes costumam se realizar via oralidade, "por contatos primários, mais próximos do concreto, da intuição sensível e da rotina da vida diária" (Nascimento, 2004, p. 85). Há de se supor que na educação escolar indígena o encontro entre saberes tradicionais e o componente curricular Matemática, nos seus moldes eurocêntricos de argumentação, demonstração e abstração, pode se tornar conflituoso. Por isso, um modo de harmonizar os estranhamentos pode ser a via de utilização de elementos culturais e históricos, como são certos artefatos e jogos.

Na legislação brasileira, são considerados Povos e Comunidades Tradicionais:

grupos culturalmente diferenciados e que se reconhecem como tais, que possuem formas próprias de organização social, que ocupam e usam territórios e recursos naturais como condição para sua reprodução cultural, social, religiosa, ancestral e econômica, utilizando conhecimentos, inovações e práticas gerados e transmitidos pela tradição (Decreto $n^{0}$ 6040, 2007).

Conhecer a historicidade e explorá-la em conjunção com ideias matemáticas a serem introduzidas na educação escolar indígena passa, então, por conhecer e reconhecer os saberes tradicionais da comunidade e viabilizar o emprego dos conhecimentos, inovações e práticas produzidos nesse encontro para a solução de problemas do grupo.

Geralmente, promover investigações sobre um possível matematizar local, dentro das matemáticas de algumas culturas, oportuniza contribuir não só localmente, mas como Onstad (2017) ressalta, até mesmo no sentido de novas perspectivas, resultados e raciocínios ainda desconhecidos dentro da matemática acadêmica mais global.

Explorar oportunamente, no contato com comunidades escolares locais, determinadas matematizações, nos fez refletir e buscar sobre jogos e brincadeiras tradicionais. Em Grando (2010) encontram-se diferentes jogos indígenas: na forma de desafios, de atividades corporais e de jogos de tabuleiros. Nesta vertente, dedicamos especial atenção a jogos que têm uma 
historicidade, são caracterizados com 'arremesso de peças' ou 'de tabuleiro' e se assemelham de algum modo a jogos da cultura indígena local, os quais são investigados como recursos didáticos a serem utilizados em oficinas e aulas de matemática. Ao mesmo tempo, no procedimento das investigações provocam-se práticas narrativas, com características das culturas indígenas envolvidas, que segundo Burke (2005, p.158) "oferecem pistas importantes para o mundo em que foram contadas", instigando interesses históricos que ajudam a constituir o delineamento de identidades.

Cabe observar que a metodologia de investigação, nas três fases apresentadas por Ponte, Brocardo e Oliveira (2009), já era uma base adequada para esse episódio que estamos narrando, e, sob a qual, os grupos de estudantes locais, da Licenciatura de Matemática do IfesVitória, e pesquisadores estavam desde o início promovendo reflexão em aula e encontros. Foi importante, nesses momentos, o papel dos professores no grupo, para que fosse discutido, coletivamente, o próprio processo em que estávamos engajados, inclusive na "procura de justificações matemáticas [dos estudantes não indígenas] para as conjecturas" (Ponte, Brocardo \& Oliveira, 2009, p. 53) a respeito dos jogos em tela. Naquele momento já ultrapassando a etapa (i) e adentrado na (ii) - a qual levou à investigação tanto bibliográfica histórica quanto no contexto indígena local.

A seguir, vamos abordar as atividades realizadas com dois jogos integrantes desse episódio envolvendo comunidades indígenas.

\section{O Milho e os Tupinikim: Um jogo de dados?}

Para Coutinho (2009), muitos jogos são reminiscências de rituais mágicos e religiosos. O autor destaca, por exemplo, o uso de dados como elementos de jogos como "descendentes dos astrágalos, búzios e outros objetos que adivinhos jogavam para ver o futuro" (Coutinho, 2009, p. 44). Embora, com as transformações sociais e culturais, os jogos tenham adquirido outros sentidos, como o lúdico. A seguir, apresentamos jogos com alguns desses materiais como peças, juntamente a um jogo do povo Tupinikim.

Em Mlodinow (2011), encontramos informações a respeito de um jogo praticado desde a Antiguidade, pelos gregos, com astrágalos de animais: 
(...) dispondo de uma abundância de carcaças animais, o que jogavam eram astrágalos, feitos de ossos do calcanhar. Um astrágalo tem seis lados, mas só quatro deles são estáveis o suficiente para permitir que o osso se apoie sobre eles. Estudiosos modernos apontam que, em virtude da anatomia do osso, as probabilidades de que caia em cada um dos lados não são iguais: são de aproximadamente $10 \%$ para dois dos lados e de $40 \%$ para os outros dois. Um jogo comum consistia em jogar 4 astrágalos. O resultado considerado como o melhor era raro, mas não o mais raro de todos: tratava-se do caso em que os 4 astrágalos caíam em lados diferentes. Tal resultado se chamava jogada de Vênus. A jogada de Vênus tem uma probabilidade de aproximadamente 384/10 mil. (Mlodinow, 2011, p.41)

Há referências a um jogo com astrágalo de boi entre os esportes tradicionalistas do Estado do Rio Grande do Sul (G1 RS, 2015), como ilustra a figura 1.

Figura 1 - Jogo do Osso

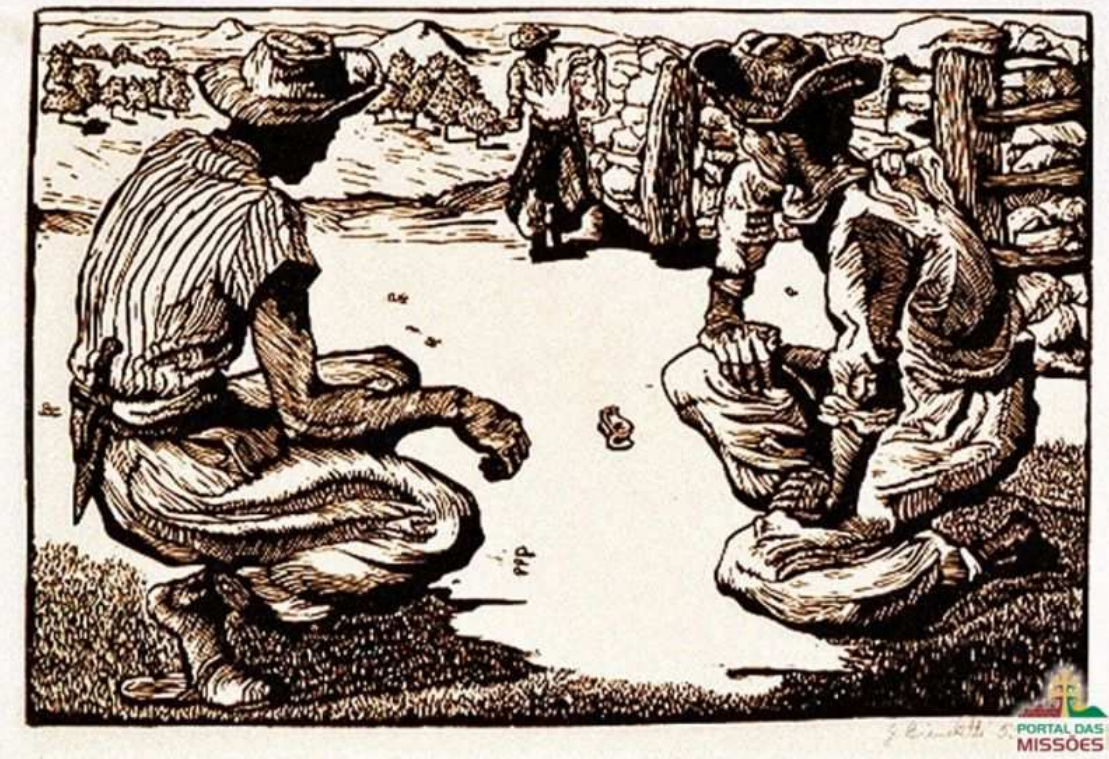

Fonte: Portal das Missões (2019).

Nessa modalidade de jogo, o astrágalo recebe duas chapas, uma de bronze e a outra de ferro, transformando-se na peça do jogo. A tava, como é chamada a peça, é arremessada por cada participante e sua posição relativa ao solo determina, criativamente, a pontuação do jogador. São consideradas 8 posições possíveis. A figura 2 mostra duas delas. 
Figura 2 - Possibilidade de Arremesso da Tava

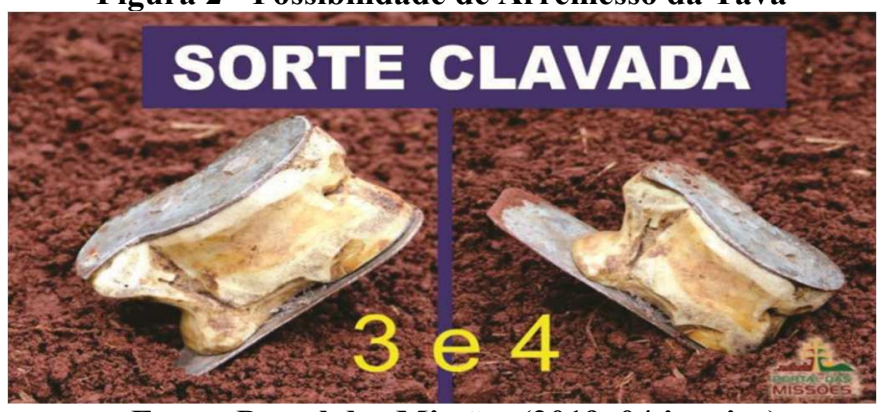

Fonte: Portal das Missões (2019, 04 janeiro).

Em Magalhães (2007), há registros de um antigo jogo praticado entre os Tupinikim no Espírito Santo em que são lançados grãos de milho sobre uma superfície. O relato colhido pela autora apresenta as regras, do que intitulamos aqui de "Jogo do Milho Queimado":

Tomávamos 6 grãos de milho e, com a ponta de um pauzinho resistente - que podia ser de cedro, bem fininho, em brasa, marcávamos o lado mais macio de cada grão. Assim, cada grão ficava com um lado marcado (queimadinho) com um ponto preto e, no outro, o mais duro e brilhoso, ficava tal como era. De um jeito que, no lado brilhoso, não pudesse transparecer o ponto marcado do outro. Assim, cada criança tomava posse de seus seis grãos marcados. Sentávamos no chão em forma de roda e combinávamos quem começaria o jogo. Com cada das mãos em forma de concha, juntas e entrelaçadas, sacudíamos as 6 pecinhas que ficavam ali dentro. Então, próximo do chão largávamos, cada um de nós, ao mesmo tempo, as peças. Contávamos as peças de cada um, que estavam no chão, mas somente as que tinham o ponto preto para cima. Aquele que tinha menos peças com pontos pretos saía do jogo. [...] E assim continuávamos até surgir o vencedor. Jogávamos várias rodadas no mesmo dia com as mesmas peças. [...] Esse é um jogo muito antigo, meus pais, meus avós, meus bisavós já jogavam. Meus bisavôs contaram que os bisavôs deles jogavam isso. (Magalhães, 2007, p. 114)

O milho é um dos principais alimentos entre os indígenas na América, faz parte de sua tradição o cultivo de variadas espécies desse cereal. O uso dos grãos no Jogo destaca esse fato. Em 2008, um Tupinikim nos fez relatos a respeito do mesmo jogo dessa vez intitulado "Jogo do Buzo", em referência aos búzios utilizados como peças em vez de grãos de milho, talvez a troca fosse favorecida pela proximidade das terras indígenas do litoral de praias, onde os búzios podem ser encontrados. Nesse caso, as partes côncava e convexa nos búzios têm o papel das faces queimadas e não-queimadas nos grãos de milho. Segundo os depoimentos, o jogo era mais comum entre os homens e jogado muitas vezes em encontros de bar. Por se tratar de "jogo de índio", foi associado a badernas e chegou a ser proibido no Município. 
Em julho de 2017, por meio do Programa Ação Saberes Indígenas na Escola, do Ministério da Educação, ministramos uma oficina de matemática para 30 professores indígenas do município de Aracruz. A oficina teve como objetivo proporcionar a experiência de um "fazer matemático", procurando levantar uma reflexão sobre a importância do jogo no contexto indígena e discutir suas potencialidades no ensino da matemática escolar. Para tanto, demos destaque ao "Jogo do Milho Queimado". Por meio dele foram realizadas discussões e atividades, inclusive com problemas matemáticos, desenvolvidas coletivamente ou em grupos menores.

Uma primeira observação sobre o Jogo foi sua semelhança com jogos 'de arremesso de peças' como o de astrágalos e mesmo de lançamento de um dado. No caso do astrágalo, os gaúchos consideram oito possíveis resultados, enquanto que os gregos antigos consideravam seis possibilidades de resultado e respectivos lados, da mesma forma que hoje podemos obter com um dado cúbico. No caso do Jogo Tupinikim, cada jogador tem 7 possibilidades de resultado quando lança seus grãos (ou búzios), conforme o número de peças com pontos pretos voltados para cima (de 0 , quando não aparecem grãos queimados, a 6 quando em todos aparecem os queimados).

Ao jogarmos na oficina com os grãos previamente preparados, percebemos que, semelhantemente a um astrágalo, alguns grãos são irregulares e podem não mostrar nenhuma das duas faces esperadas. O jogo original traz a situação da escolha dos grãos e do seu preparo por cada jogador, e daí a vantagem de integrar estudantes-participantes no preparo do material, com a produção e controle dos mesmos, fomentando a autonomia e a criatividade no uso e aproveitamento de materiais.

A oficina estimulou nos participantes o interesse pelo uso de jogos e brincadeiras na educação escolar, como reconhecimento do papel dos jogos na identidade dos povos indígenas, como ilustra o depoimento a seguir:

Achei importante a formação de hoje, pois os alunos precisam realmente de um ensino diferenciado e descontraído, pois, crianças aprendem muito mais através de brincadeiras. Na aldeia, as crianças aprendem a pescar, brincando de pescar. Aprendem a fazer casa, brincando de fazer casa. É assim com armadilhas e artesanatos. (Depoimento de professor indígena, Acervo das autoras, 2017) 
Motivados pelo "Jogo do milho queimado", alguns professores têm buscado identificar outros jogos tradicionais. Posteriormente ao momento da oficina, muitos relataram o quão positivas foram as experiências com o jogo em suas respectivas salas de aula, estimulando a atividades básicas como contar, agrupar (classificar) e inferir. Ademais, incentiva a continuar investigando historicamente em meio às especificidades culturais indígenas, atuando e trocando experiências com eles, na pretensão conjunta de contribuir à historicidade de suas tradições carregadas de vestígios culturais antigos que apresentam potencialidades, ainda hoje, de serem trabalhadas na educação escolar indígena.

Observamos que a atividade com o Jogo foi aos poucos sendo apropriada, qualitativamente, em termos de organização entre os participantes, criação de regras, estratégia e de conjecturas em casos específicos de determinados números de jogadores, lançamentos e resultados. Adicionamos a isso, a elaboração de relatos e de relatórios pelos estudantes que participaram, os quais "mostram que a qualidade da argumentação dos alunos pode melhorar com a redação continuada de relatórios escritos”. (Ponte, 2003, p. 28).

\section{Os Guarani e o Jogo da Onça}

Existem imprecisões quanto às origens de muitos dos jogos antigos de tabuleiro, mesmo porque eles sofrem transformações com o tempo e os diversos contatos culturais, convergindo com o comentário de Alves (2003, p.5) quando afirma que "jogos tradicionais brasileiros carregam a marca de nossa miscigenação, a mistura do europeu (essencialmente o português), do negro e do índio fez surgir uma combinação genética e cultural influenciando a vida social do brasileiro".

Nesse sentido, também está o alerta de Grando (2010) a respeito da falta de registros sobre a origem dos jogos indígenas, se foram criados pelos indígenas ou aprendidos com os colonizadores, subjugados pelo dominador e miscigenando algumas ideias e costumes. Talvez por isso, no caso do jogo de tabuleiro indígena tradicional observado entre os Guarani, tenhamos verificado proximidades de regras, movimentos e peças. Em geral, esses jogos são caracterizados por simulações, nas quais "todas as situações visam planejar, avaliar e calcular sua posição em um jogo, real ou não, figurando ensinamentos que têm na base a estratégia" (Ferreira,Vinha \& Souza, 2008, p. 49). 
Alguns jogos de tabuleiro derivam de arquiteturas de templos sagrados, e foram talhados em diversos materiais, os "objetos (pedras, figuras etc.) por vezes simbolizam pessoas ou animais ferozes, ambos com poderes que estimulam desafios" e contribuem para "refletir sobre as representações sociais da sociedade que o pratica" (Vinha, 2010, p.27). Ou seja, até se tornar um jogo tido como tradicional, ele vai agregando significados que são moldados pela sociedade do local que o adota. Exemplos podem ser citados também em outros continentes, como o Bagh Chal (figura 3), do Nepal, que representa uma batalha entre tigres e cabras (Perera; Oliveras \& Oliveras, 2016) ou o antigo jogo viking Hnefatafl (figura 4) que simula sagas medievais. O Hnefatafl inicia com forças desiguais e representa estratégias tomadas por reis e exércitos para expansão, trazendo semelhanças com alguns jogos de padrão europeu como xadrez.

Figura 3 - Tabuleiro decorado do Bagh Chal e representação das peças
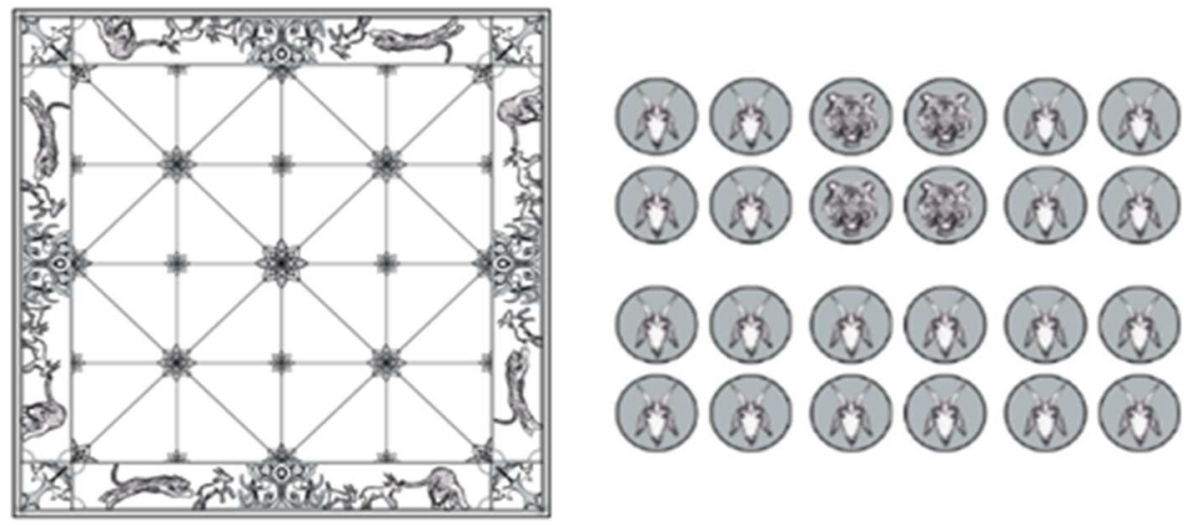

Fonte: Perera, Oliveras \& Oliveras, 2016.

Figura 4 - Tabuleiro e peças do Hnefatafl

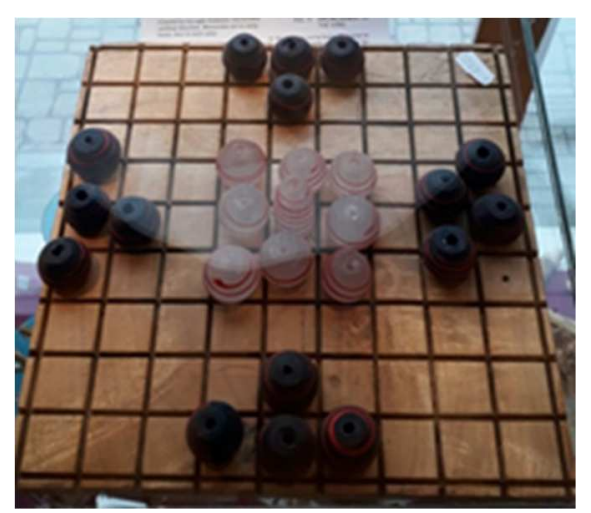

Fonte: Acervo das autoras, Oslo, 2017. 
O jogo de tabuleiro indígena que evidenciamos aqui é o denominado Jogo da Onça que também inicia com forças desiguais, quais sejam a onça e os cachorros. Segundo Grando (2010), o jogo é encontrado nos primeiros registros históricos dos grupos étnicos entre os Manchakeri (Acre), os Bororo (Mato Grosso), e os Guarani (São Paulo).

O Jogo da Onça também é conhecido como Jogo da Onça e dos cachorros, porque envolve, além da imponente e importante figura do animal onça, 14 cachorros como personagens. As peças representam força e ataque, a onça mostrando sua força e os cachorros habilidade de ganhar com o ataque em alcateia. O tabuleiro é habitualmente traçado na terra e pedras são usadas como peças na representação do tabuleiro. De modo especial, observamos o quanto os estudantes demonstraram vontade para engajar-se nos grupos e jogar! O que, segundo Vygotski (1995), é influência da sensação interna de afeto, corroborada pelo ambiente social e cultural constituído. Além disso, as crianças participantes se esmeraram nas construções de seus respectivos tabuleiros, buscando inclusive criar as condições do contexto do jogo com materiais alternativos, para na sequência usarem de concentração e abstração como se fossem os próprios personagens (onça e cachorros) reificados.

A figura 5 (foto) mostra o tabuleiro confeccionado por um aluno de $5^{\circ}$ ano na Escola Guarani, em uma das ações do jogo, com as peças na posição inicial. Na sua abstração, as pedras brancas representam os cachorros e a pedra colorida representa a onça.

Figura 5 - Tabuleiro e peças de Jogo da Onça

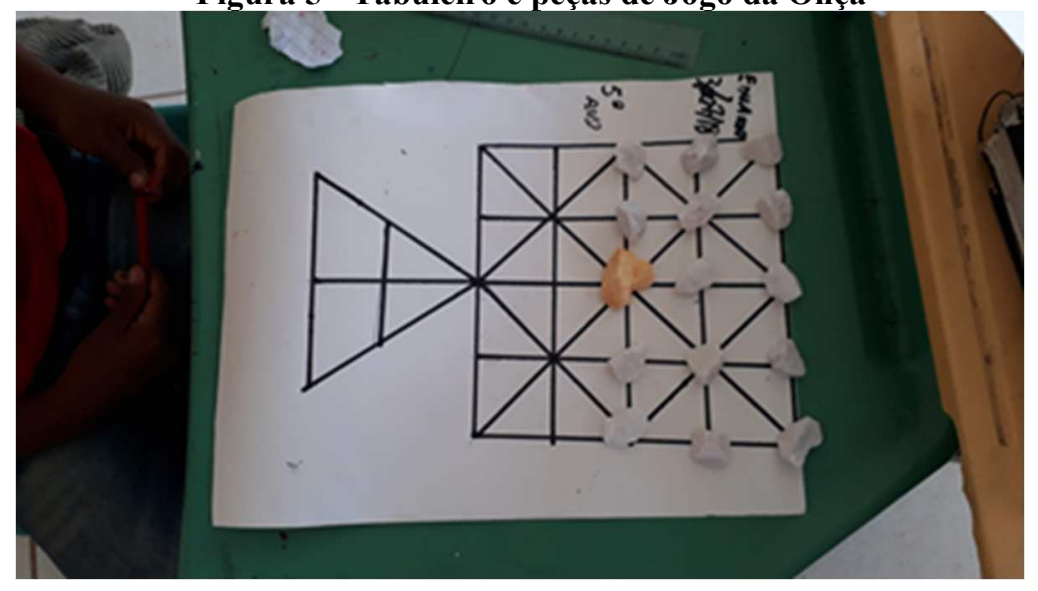

Fonte: Acervo das autoras, 2018.

As regras do Jogo da Onça são descritas com base em Lima \& Barreto (2005), sendo que é disputado em dupla de jogadores. Um jogador fica com a onça (centro do tabuleiro) e 
outro com os 14 cachorros nos lugares marcados atrás da onça. O jogador com a onça inicia a partida movendo sua peça para qualquer casa adjacente que esteja vazia. Qualquer movimento, da onça ou dos cachorros, deve seguir pelas linhas - segmentos de reta traçados no tabuleiro. O jogador com os cachorros move qualquer uma de suas peças também para uma casa adjacente que esteja vazia, alternando as jogadas com o jogador com a onça. As peças podem se mover em qualquer direção. Uma das estratégias da onça é tomar cuidado para não entrar em sua toca (parte triangular do tabuleiro). Caso isso aconteça, ela poderá ser mais facilmente encurralada pelos cachorros. A onça captura um cachorro quando salta sobre ele para uma casa vazia (apesar de não pode saltar dois juntos), mas os cachorros não podem pular sobre a onça. A captura da onça pode acontecer em qualquer sentido em que ela não puder mais se mexer. O jogador com a onça não pode fazer mais de uma captura de cachorros na mesma jogada, mesmo que haja a possibilidade. Vence a partida o jogador com a onça se consegue capturar cinco cachorros ou o jogador com os cachorros quando consegue imobilizar a onça.

Nas palavras do professor guarani Mauro Carvalho (Karai), "o jogo é igual à natureza" (Carvalho Guarani, 2018), pois representa a relação entre os dois personagens: a onça é capaz de matar um cachorro, mas eles juntos conseguem cercá-la ou afugentá-la. A presença desses animais na memória cultural dos Guarani se expressa, por exemplo, na narrativa de uma anciã colhida por uma de suas netas:

Numa floresta distante havia uma onça e um bando de cachorros. Certo dia, a onça foi até os cachorros e quando ele chegou os cachorros o cercaram.

Então, a onça ficou com muita raiva, e pegou um dos cachorros e comeu. Logo fugiu, voltando para sua toca.

Os cachorros ficaram muito tristes porque a onça comeu um cachorro, e resolveram ir à casa da onça e falaram para ela:

-Queremos que você vá embora dessa floresta!

$\mathrm{E}$ a onça respondeu:

Não irei! E SAIAM DA MINHA CASA!

Assim, os cachorros foram embora e noutro dia falaram novamente na toca da onça, porém, desta vez levaram carne, e lhe perguntaram:

-Por que você matou e comeu um de nós? Por isso queremos que você vá embora daqui.

E então a onça lhes disse:

-Irei embora, mas quero que vocês tragam muita carne para mim.

$\mathrm{E}$ assim os cachorros fizeram, trouxeram bastante carne, a onça encheu a barriga e foi embora. E nunca mais foi vista naquela floresta.

E os cachorros viveram felizes para sempre. (Acervo das autoras, 2018) 
Entre os Guarani no Espírito Santo, encontramos uma outra versão de jogo de tabuleiro, dessa vez simulando uma disputa entre "gatinhos e ratinhos", como nos relatou a mesma anciã em 2017. Elementos históricos locais e mais detalhes do jogo ainda estão em fase de investigação. Contudo, abrimos espaço para reforçar que, conforme analisado no jogo anterior, a integração com o contexto da comunidade e participação na elaboração de elementos do jogo, fomentam a autonomia e a criatividade das escolhas.

Algumas características identificadas no Jogo dos Guarani no Estado são o tabuleiro, formado por 42 casas dispostas em 7 fileiras de 6 casas cada uma, e o número de 12 peças para cada um dos dois jogadores. O jogador tem como objetivo ganhar as peças do adversário ou criar uma disposição de peças que impeça qualquer movimento às pedras do adversário.

No envolvimento do jogar, esses dois jogos permitem explorar o desenho, medição e escala, por exemplo, na construção do tabuleiro (segmentos cruzados, paralelos e perpendiculares), ou reconhecimento de polígonos e suas propriedades, além de ideias de contagem e operações, entre outras. Contudo, esse é um olhar dentro dos significados da matemática escolar não indígena, que pode ser utilizada no fazer matemático da escola indígena.

Ambos os jogos indígenas de tabuleiro, anteriormente mencionados, têm aproximações com o jogo Alquerque, que se acredita tenha chegado à Europa pelos árabes, onde era nomeado Al-Quirkat, embora haja origens remotas (figura 6) de tabuleiros de pedras semelhantes no templo egípcio de Kurna, em 1400 a.C., conforme Millán (2012).

Figura 6 - Tabuleiro de Alquerque Igreja de N. Sra. da Oliveira, Braga, Portugal

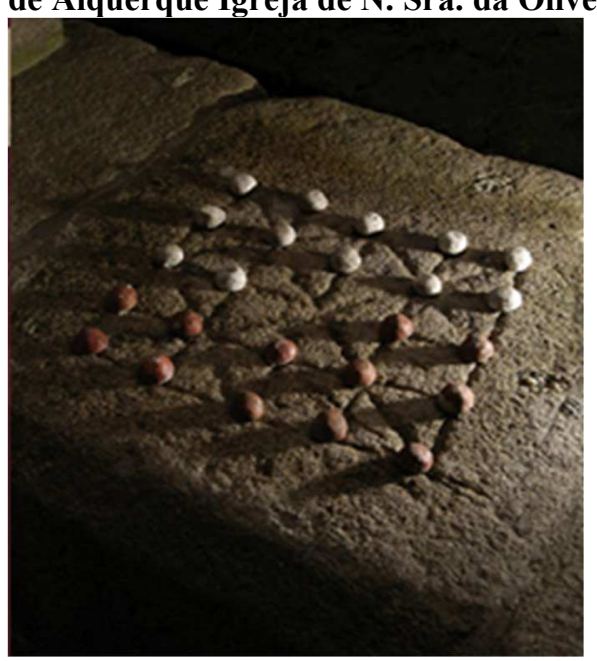

Fonte: Carreira; Alberto \& Fernandes (2004). 
Desse jogo do Alquerque existem centenas de variantes e aproximações, como notamos em relação aos dois jogos indígenas que anteriormente apresentamos. Em especial, no tipo de tabuleiro, jogo a dois e a locomoção das várias peças, além de semelhanças no modo das estratégias do jogar.

Outros exemplos de similitude de jogos talvez pudessem ser levantados nessa busca de construção de aprofundamento da historicidade dos jogos indígenas locais e suas possíveis relações com o fazer matemático, mas devido ao caminhar da pesquisa do grupo, nos restringimos a indicar estas.

\section{Episódio 2 - O Teorema de Pitágoras com recursos de um Curso Técnico de Mecânica}

O episódio apresentado aqui ocorreu como uma atividade extracurricular desenvolvida por três alunos de $1^{\circ}$ ano de um Curso Técnico em Mecânica Integrado ao Ensino Médio do Instituto Federal do Espírito Santo com a orientação e participação de sua professora de Matemática, uma das autoras do presente texto, com a finalidade de ser exposto na Feira de Matemática do Ifes, campus Vitória em 2019. A atividade teve como tema de estudo e investigações o Teorema de Pitágoras, destacando a sua importância ao longo do tempo por meio de menções que extrapolam o mundo matemático, revelando a sua popularidade, ainda que permeada de falhas e equívocos de interpretação. $O$ que segue foi resultado da investigação do grupo de alunos, orientados pela professora quanto a algumas escolhas para a elaboração escrita e apresentação (Puente, Visintini, Souza , \& Lorenzoni , 2019).

Enquanto um dos assuntos mais conhecidos da Matemática, o Teorema de Pitágoras possui um enunciado relativamente simples: Em um triângulo retângulo, o quadrado do comprimento da hipotenusa é igual à soma dos quadrados dos comprimentos dos catetos. Sua abordagem pelo matemático grego Pitágoras de Samos, ou algum de seus discípulos, por volta dos anos 500 a.C., teve um papel fundamental no desenvolvimento científico e tecnológico da sociedade global, não só por se constituir numa ferramenta de resolução de problemas, mas por ter despertado o espírito investigativo de estudiosos e cientistas provocando avanços na matemática até os dias atuais. 
Apontado por Stewart (2012) como, provavelmente, a mais célebre e recordada expressão matemática, ou sem dúvida, a mais famosa entre as elaborações pitagóricas (Kline, 1999), o Teorema de Pitágoras tem também suas versões criativas que contribuem para a disseminação e compreensão de ideias matemáticas, quando lhe são leais. Algumas revelam equívocos de interpretação que o trabalho buscou contrapor, com escolhas iniciadas durante a primeira fase das investigações, para se fazer justiça ao enunciado, apresentando versões historicamente validadas. Para tanto, o trabalho buscou apresentar o Teorema de Pitágoras do ponto de vista matemático, sem perder de vista sua contextualização histórica, importante ao reconhecimento da matemática como uma construção vinculada à história da humanidade.

Diante das perspectivas propostas, três aspectos distintos de observação do Teorema foram considerados: matemático, histórico e artístico. Em relação ao aspecto matemático, foram investigados os princípios do Teorema, sua relação com o triângulo retângulo (catetos e hipotenusa) e sua aplicação em diferentes problemas matemáticos. Sobre o aspecto histórico, investigou-se o período de atividade de Pitágoras de Samos, a criação da Escola Pitagórica e o possível processo de elaboração do enunciado do Teorema. Segundo afirmação de historiadores (Kline 1999; Roque, 2012), é duvidoso que tenham demonstrado nessa época o Teorema, uma vez que não conheciam resultados teóricos de semelhança de triângulos e, geralmente, as justificações eram a partir de casos particulares. Posteriormente, o tratamento dado ao mesmo teorema por outros personagens da Grécia Antiga, como a atribuição de Proclus a Euclides de Alexandria (300 a.C.) como sendo o mentor da demonstração (figura 7) apresentada na proposição 47 do Livro I da obra "Elementos” de Euclides (Kline 1999; Boyer, 1996). Consideramos que tal abordagem de aspectos históricos do Teorema reforça a importância de se reconhecer a Matemática como uma criação humana, cujo "rigor" das demonstrações aceitas foi sendo transformado e a História da Matemática como fonte de possibilidades para um “fazer matemática” na Educação Básica (Lorenzoni \& Sad, 2018). 
Figura 7 - Diagramas da proposição I.47 de Euclides em um manuscrito árabe do séc. XIII (à esquerda) e em um cenário da Primeira Guerra Mundial (à direita)
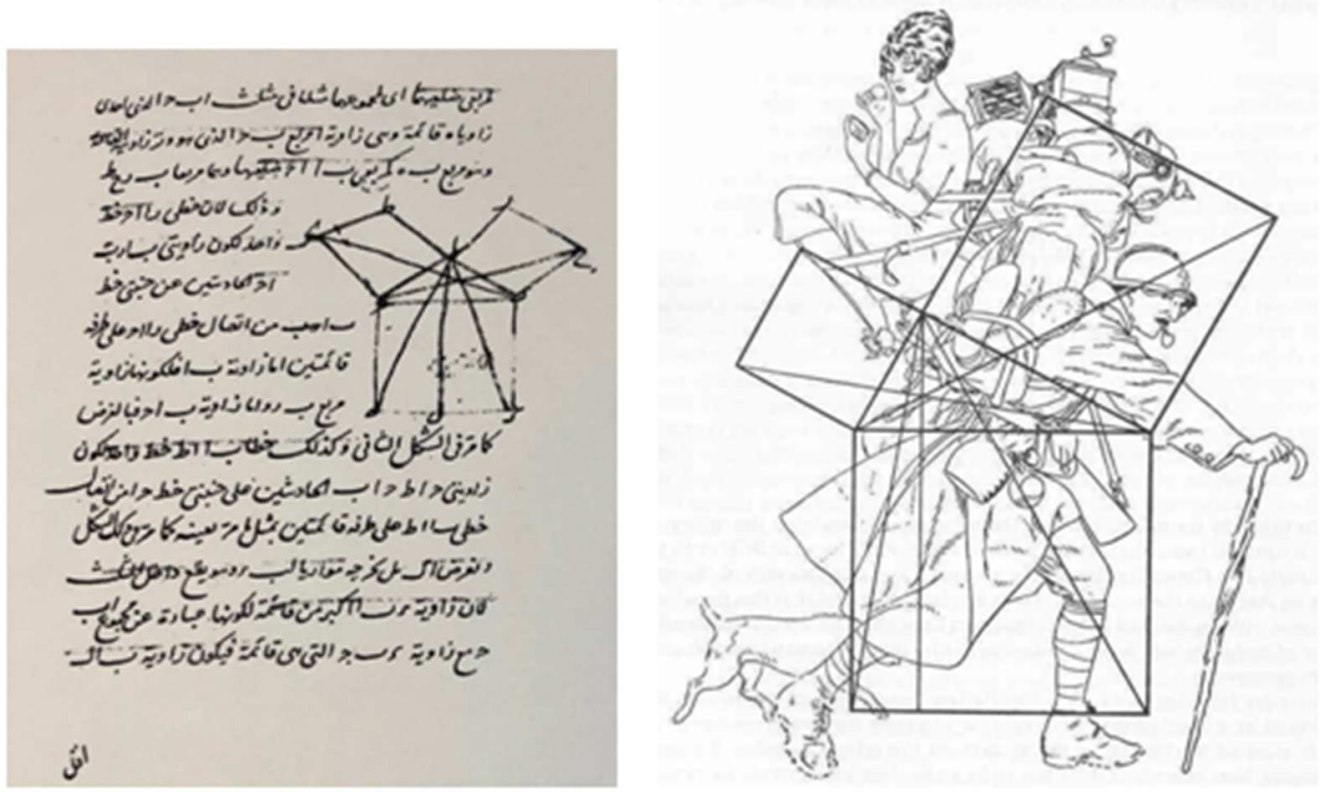

Fonte (imagem esquerda): Guardeño (2000, p. 44); Fonte (imagem direita): Boyer (1996, p.80).

Além disso, observou-se a importância do Teorema para o desenvolvimento da Matemática e de outras ciências, como a Física e a Astronomia, em séculos posteriores a Pitágoras, e suas repercussões no ensino de matemática, inclusive no Brasil. Em 1870, Raymundo Teixeira Mendes, um estudante do então Imperial Collegio de Pedro II do Rio de Janeiro, aos 16 anos de idade, usando sua criatividade, propôs sua própria demonstração do Teorema (Silva \& Lorenzoni, 2002). Finalmente, tratando-se do aspecto artístico, foram feitas pesquisas bibliográficas em obras como "Os Segredos Matemáticos dos Simpsons" (Singh, 2016), "Poesia Matemática" (Fernandes, 2009) e o filme "O Mágico de Oz" (Fleming, Vidor, \& Cukor, 1939), baseado no livro homônimo de 1900 (Baum, 2013).

A fase de investigação sobre o tema foi providencial para relacionar os diferentes aspectos do Teorema de Pitágoras, lembrar e discutir conceitos já estudados, produzindo significados novos (Ponte; Brocado \& Oliveira, 2009). Como consequência, isso tornou possível o direcionamento às formas de apresentação do trabalho durante a exposição dos alunos na Feira de Matemática, descrita no início desse episódio. 
Além da exposição do tema, a criatividade do grupo foi suscitada pela professora e aproveitada para a confecção de uma representação, com auxílio de massa de modelar, da demonstração de Euclides de Alexandria para o Teorema de Pitágoras. A massa de modelar foi usada para preencher fôrmas metálicas, confeccionadas pelos autores em parceria com dois outros estudantes e um professor do Curso Técnico em Mecânica Integrado ao Ensino Médio, especificamente para ilustrar a demonstração, segundo Euclides, de que, num triângulo retângulo, a área do quadrado de lado igual à hipotenusa é igual à soma das áreas dos quadrados de lados iguais aos catetos. De fato, o material (figura 8), sendo tridimensional, remete à comparação de volumes dos sólidos construídos em forma de paralelepípedos. No entanto, todos possuem mesma altura quando dispostos como nas imagens. Do que se pode concluir também uma equivalências de áreas.
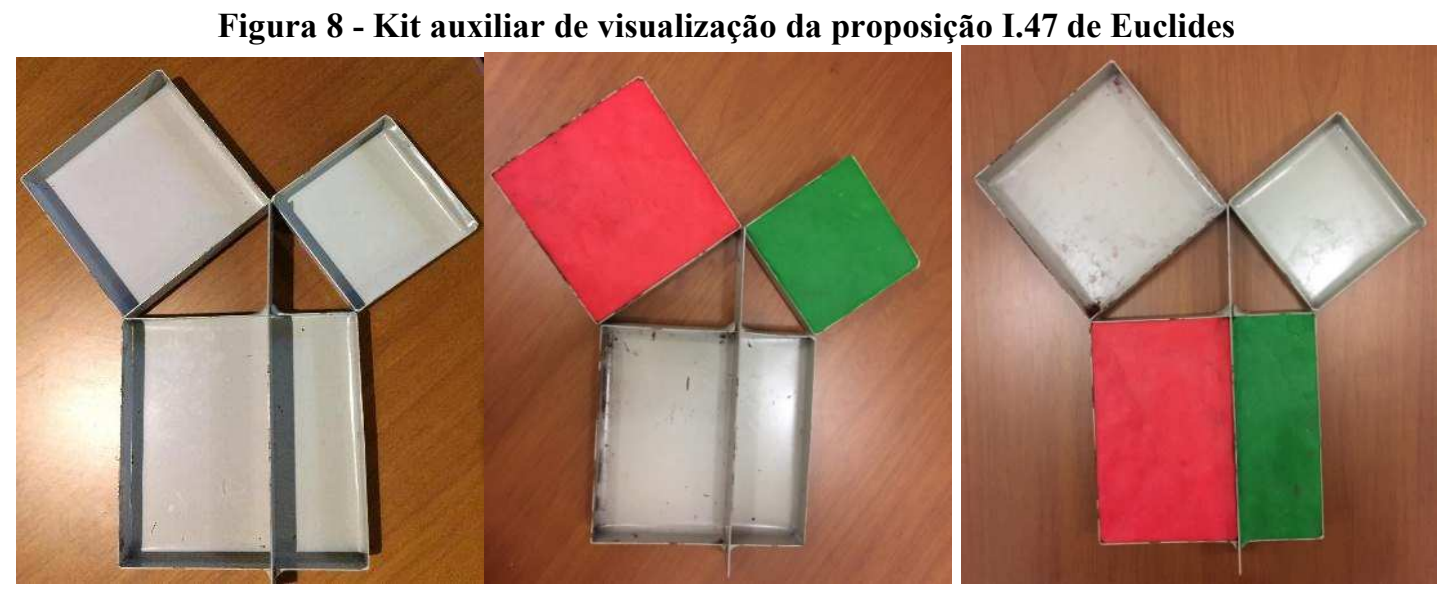

Fonte: Acervo das autoras, 2019.

Assim, os presentes na Feira puderam explorar, por meio de atividades interativas, os erros ou acertos de versões do Teorema como o verso de Millôr Fernandes (2009), quando se diz "Sou a soma dos quadrados dos catetos, mas pode me chamar de hipotenusa", e a cena do filme "O Mágico de Oz" (1939), quando o Espantalho diz que "A soma da raiz quadrada de dois lados de um triângulo isósceles é igual a raiz quadrada do terceiro lado". Além do kit da Figura 6, o grupo usou também como recursos um painel com representações da Hipotenusa de Fernandes (2009), do Espantalho de Oz e possíveis falas para os personagens segundo o Teorema de Pitágoras; e um quebra-cabeça, em referência à representação chinesa. Este último 
foi construído por iniciativa de um dos estudantes, com auxílio de seu pai. Por motivos de ética em pesquisa, chamaremos o referido estudante de Sol.

A escolha do teorema de Pitágoras baseou-se no reconhecimento de que representa um dos importantes teoremas da matemática, com aplicações em diversas áreas de atuação humana, o que lhe permite gozar de uma popularidade que ultrapassa o mundo acadêmico, sendo uma das expressões matemáticas mais recordadas, ainda que permeada por equívocos de interpretação que, mesmo merecendo ser criticados, devem ser reconhecidos por sua colaboração à superação da imagem excessivamente abstrata que a Matemática costuma ocupar no imaginário popular. Como por exemplo, levantar questionamentos em torno da questão histórica da importância da busca de ternos pitagóricos para obtenção do ângulo reto.

Assim, além de tratar de demonstrações matemáticas do Teorema, foram discutidas aplicações que utilizaram o resultado em diferentes regiões do mundo, algumas em soluções de problemas tanto ou mais antigos que dos gregos, como a solução chinesa do Problema do bambu quebrado, no $9^{\circ}$ capítulo do antigo livro Nove Capítulos sobre a Arte da Matemática (título original: Chiu Chang Suan Shu) no início da era cristã. (Estrada et al, 2000). De Euclides de Alexandria, o trabalho abordou menções a ele encontradas no universo artístico, na poesia e no cinema, ressaltando os equívocos de interpretação e apontando sua expressão considerada válida. Ademais, o trabalho buscou contextualizar historicamente o Teorema de Pitágoras pela importância de se reconhecer a matemática como uma criação humana, vinculada à história da humanidade e fruto, portanto, de seu desenvolvimento intelectual e social.

A apresentação do trabalho "Pitágoras e o Espantalho: Entre Teoremas e Equívocos" na $8^{\text {a }}$ Feira de Matemática do IFES foi uma experiência extremamente proveitosa e de enorme valor contribuinte para os meus conhecimentos e vivências que extrapolam as atividades curriculares escolares básicas. O trabalho exigiu grande empenho e conhecimento de diversos aspectos: inicialmente foram necessárias extensas pesquisas voltadas à elaboração da parte escrita e da construção conceitual do trabalho; depois, precisamos decidir e idealizar de que forma e com que materiais apresentaríamos nosso trabalho ao público, e quais seriam os meios, ao mesmo tempo viáveis e convincentes, para seu entendimento; foi também necessário que confeccionássemos nossos próprios instrumentos, conciliando, inclusive, por meio do auxílio de colegas do $3^{\circ}$ ano, os processos ao curso técnico de mecânica. Por fim, nos envolvemos no processo final e mais esperado, que considero ser o de maior aprendizagem oferecido aos alunos que apresentam trabalhos na feira: reunir todo o conhecimento e ideias atribuídos ao tema proposto e transmiti-los ao público da melhor maneira possível, sabendo nos colocar no lugar das pessoas para as quais 
História da matemática na educação matemática, uma via de investigação, criatividade...

apresentávamos, tornando o conteúdo volúvel, e mais simples ou complexo conforme a demanda dos visitantes. (Registros do aluno de pseudônimo Sol, participante no Episódio 2).

Observamos que alguns alunos participantes que conseguiram expressar-se, como o desse depoimento, não nos deixaram qualquer dúvida de que o desenvolvimento alcançado superou nossas expectativas quanto a essa situação, a qual somente se delineou ao longo dos procedimentos e tornou a última fase da atividade de investigação chamativa a outras. Concordamos com (Ponte; Brocado \& Oliveira, 2009, p. 24) quando afirmam que "O grande desafio é articular esses diferentes tipos de tarefa de modo a constituir um currículo interessante e equilibrado, capaz de promover o desenvolvimento matemático dos alunos com diferentes níveis de desempenho".

Em termos dos relatos e relatórios avaliativos, ao final desse Episódio, cabe destacar que houve ganho em aprendizagens matemáticas, mas também, em relação a suas atitudes positivas quanto aos desenvolvimentos investigativos e de produção criativa, a fim de tornarem a apresentação do Teorema algo "chamativo" e instigador a quem estivesse na Feira.

\section{Como considerações finais}

Do ponto de vista da história da matemática, a formação de um fazer matemático histórico, ensejado por jogos culturais tradicionais entre os Guarani e Tupinikim do Espírito Santo, instigou a investigações no campo epistemológico da constituição de planejamento e combinações para as atividades básicas de matematizar.

Diante das observações e das atividades partilhadas, bem como dos rastros históricos obtidos como dados da pesquisa até o momento, acreditamos que uma abordagem de saberes tradicionais na perspectiva de uma história da matemática (ou da história de um matematizar) pode contribuir para uma educação matemática indígena e não indígena com mais significado e proporcionar subsídios de interesse à historicidade dos grupos indígenas locais.

O Episódio 2, que narra a experiência com o Teorema de Pitágoras em uma feira de matemática, partiu de uma ação investigativa da História da Matemática, fomentando a produção de conhecimento e fomentando a criatividade de modo entrelaçado e de igual importância. A iniciativa do estudante Sol, em colaboração com outros, de construir o quebracabeça para verificação do Teorema de Pitágoras, ocorrida no decorrer da pesquisa, sinaliza 
uma etapa no seu processo de construção do conhecimento de demonstrações do Teorema por decomposição de áreas. Essa iniciativa revela ainda a capacidade potencial de Sol para criar uma coisa 'única', nova naquele seu contexto, como propõem Karwowski, Jankovska \& Szwajkowski (2017). A ação de pesquisa com articulação dos membros do grupo entre si, inclusive com a professora orientadora, e com colegas de outras turmas foi um campo fértil para o exercício da capacidade de transformação, destacada também por esses autores. Os potes de massa de modelar, talvez restantes de uma fase anterior de escolaridade dos estudantes, associados às chapas de aço da ferramentaria do campus ganharam novas potencialidades e significados no universo escolar, com capacidade de propagar, entre os visitantes da exposição, experiências semelhantes de construção e negociação de significados quanto ao Teorema de Pitágoras e suas demonstrações.

Em síntese, apesar de todos os desafios enfrentados nas vivências que apresentamos, discutimos, apontamos como resultado - poder unir teorias e ideias científicas ao analisar potencialidades e contribuições da História da Matemática em práticas docentes do ensino da matemática escolar, envolvendo a investigação e a criatividade em metodologias híbridas e contextos de diferentes culturas.

\section{REFERÊNCIAS BIBLIOGRÁFICAS}

Alves, A. M. (2003). A história dos jogos e a constituição da cultura lúdica. Revista Linhas, 4, n.1. Acesso em 05 de abril de 2020, disponível em http://www.revistas.udesc.br/index.php/linhas/article/view/1203

Barbin, E. (2006) Apports de l'histoire des mathématiques et de l'histoire des sciences dans l'enseignement , Tréma, 26 , 2006, 20-28.

Bishop, A. (1999). Enculturación Matemática: La educación matemática desde uma perspectiva cultural. Barcelona, Espãna: Pidós Ibérica.

Boyer, C. B. (1996). História da Matemática. São Paulo: Edgar Blucher.

Brasil. (1996). Lei 9.394, de 20 de dezembro de 1996. Estabelece as Diretrizes e Bases da Educação Nacional. Diário Oficial da União. Brasília, DF, v. 134, n. 248, p. 27833-841, 23 dez. 1996.

Brasil MEC. (1998). Parâmetros Curriculares Nacionais: Matemática. Brasília: Ministério da Educação, Secretaria de Educação Fundamental. 
Brasil IBGE. (2013). O Brasil indígena. Distribuição Espacial da População Indígena. Brasil: Fundação Nacional do Índio. (Folder) Acesso em 05 de abril de 2020, disponível em http://www.funai.gov.br/arquivos/conteudo/ascom/2013/img/12-

Dez/encarte_censo_indigena_02\%20B.pdf

Brasil MEC. (2018). Base Nacional Comum Curricular: Ensino Médio. Brasília: MEC/Secretaria de Educação Básica, 2018.

Brasil MS (2019). Saúde indígena: análise da situação de saúde no SasiSUS. Brasília: Ministério da Saúde. Acesso em 05 de abril de 2019, disponível em http://bvsms.saude.gov.br/bvs/publicacoes/saude_indigena_analise_situacao_sasisus.pdf

Boyer, C. B. (1974). História da Matemática. Tradução Elza Gomide. São Paulo: Edgard Blüche, USP.

Burke, P. (2005). O que é história cultural? (S. G. Paula, Trad.) Rio de Janeiro: Jorge Zahar.

Carvalho, M. L. (2018, agosto). Depoimento: Mauro Luiz Carvalho (Guarani). Depoimento concedido a C. A. C. A. Lorenzoni. Aracruz. Mimeografado.

Coutinho, L. F. (2009). Mehinaku: Desing gráfico de um jogo de tabuleiro. Monografia (Monografia em Desenho Industrial), FAAP - Fundação Armando Álvares Penteado, São Paulo. Acesso em 25 de dezembro de 2018, disponível em https://issuu.com/lfbaroni/docs/mehinaku

D'Ambrosio, U. (2001). Etnomatemática: Elo entre as tradições e a modernidade. Belo Horizonte: Autêntica.

Decreto $\mathrm{n}^{\mathrm{o}}$ 6040, de 07 de fevereiro de 2007. (07 de fevereiro de 2007). Institui a Política Nacional de Desenvolvimento Sustentável dos Povos e Comunidades Tradicionais. Diário Oficial da União. Recuperado a partir de http://www.planalto.gov.br/ccivil 03/ ato20072010/2007/decreto/d6040.htm

Diegues, A. C.; Arruda, R. S. V. (Orgs). (2001). Saberes tradicionais e biodiversidade no Brasil. Brasília: Ministério do Meio Ambiente; São Paulo: USP.

Fernandes, M. (2009). Poesia Matemática. Rio de Janeiro: Desiderata.

Ferreira, M. K. L. (1998). Madikauku: os dez dedos das mãos, matemática e povos indígenas no Brasil. Brasília: MEC.

Ferreira, M. B., Vinha, M., \& Souza, A. F. (2008). Jogos de tabuleiro: um percurso em etnias. Revista Brasileira de Ciência e Movimento, 16 (1), pp. 47-55.

Fleming, V., Vidor, K., \& Cukor, G. (Diretores). (1939). O Mágico de Oz [Filme Cinematográfico]. Título Original: The Wizard of Oz. Warner Bros.

G1 RS. (03 de setembro de 2015). Jogos Farroupilhas: conheça as regras do Jogo do Osso. Acesso em 01 de abril de 2020, disponível em http://g1.globo.com/rs/rio-grande-do- 
sul/semana-farroupilha/2015/noticia/2015/09/jogos-farroupilhas-conheca-regras-do-jogo-doosso.html

Gardeño, A. J. D. (2000). El legado de las Matemáticas: De Euclides a Newton, los gênios a través de sus libros. Sevilla: Consejería de Cultura.

Gerlovina, Z. (2011). Eureka! Unraveling the mystery behind creativity. Switzerland: Springer International Publishing.

Guillemette, D. (2017). History of mathematics in secondary school teachers' training: towards a nonviolent mathematics education. Educational Studies in Mathematics, 96.

Grando, B. S. (2010). Jogos e culturas indígenas: Possibilidades para a educação intercultural. Cuiabá: EdUFMT.

Jankvist, U.T. (2009). A categorization of the "whys" and "hows" of using history in mathematics education. Educational Studies in Mathematics, v.71, n. 3, p. 235-261.

Karwowski, M.; Jankowska, D. M.; Szwajkowski , W. Creativity, Imagination, and Early Mathematics Education. In: Leikin, R. Sriraman, B. (eds.). (2017). Creativity and Giftedness. Switzerland: Springer International Publishing .

Kline, M. (1999). El pensamiento matemático desde la antigüedad a nuestros días. Madrid: Alianza Editorial.

Lima, M. d., \& Barreto, A. (2005). O Jogo da Onça e Outras Brincadeiras Indígenas. São Paulo: Panda Books.

Lorenzoni, C. A. (2014). Os Guarani do Espírito Santo: Um estudo de motivos gráficos da cestaria. In: S. Nobre, F. Bertato, \& L. Saraiva (Ed.), $6^{\circ}$ Encontro Luso-Brasileiro de História da Matemática (pp. 889-909). São João del Rei: Sociedade Brasileira de História da Matemática - SBHMat.

Lorenzoni, C. A., \& Sad, L. A. (2018). História da Matemática e o "fazer matemática" na Educação Básica. HISTEMAT - Revista de História da Educação Matemática, Ano 4. v. 1, pp. 75-89.

Magalhães, D. R. (2007). Concepções, crenças e atitudes dos educadores tupinikim frente à matemática. Dissertação de Mestrado, Universidade Federal do Espírito Santo, Programa de Pós-Graduação em Educação, Vitória.

Mendes, I. (2009). Atividades históricas para o ensino de Trigonometria. In: Miguel, A. et al. História da Matemática em atividades didáticas. 2 ed. São Paulo: Livraria da Física.

Millán, G. P. (2012). Los Juegos de mesa: Creación y producción. Dissertação de Mestrado, Universidad de Granada, Granada, España.

Mlodinow, L. (2011). O andar do bêbado. Como o acaso determina nossas vidas. Rio de Janeiro: Zahar. 
Nascimento, A. C. (2004). Escola indigena: Palco das diferenças. Campo Grande: UCDB.

Onstad, T. (December de 2017). Is the Mathematics We See the Mathematics They Do? Journal of Mathematics and Culture, 11, pp. 133-159.

Perera, C. S., Oliveras, A. F., \& Oliveras, M. (2016). Play in Scientific and Mathematical Non-Formal Education: Bagh Chal, a Tigers-and-Goats Game. In: Z. Bekirogullari (Ed.), The European Proceedings of Social \& Behavioural Sciences EpSBS: 4th Annual International Conference on Cognitive - Social, and Behavioural Sciences. VIII, pp. 178-191. UK: Future Academy. doi:http://dx.doi.org/10.15405/epsbs.2016.05.19

Ponte, J. P. (2003). Investigação sobre investigações matemáticas em Portugal. Investigar em Educação, p. 93-169.

Ponte, J. P, Brocardo, J.; Oliveira, H. (2013). Investigações Matemáticas na sala de Aula. Belo Horizonte: Autêntica.

Portal das Missões (2019, 02 janeiro). Tava ou o Jogo do Osso. [Site]. Recuperado a partir de http://www.portaldasmissoes.com.br/site/view/id/1450/status/success

Portal das Missões (2019, 04 janeiro). Tava ou o Jogo do Osso. [Site]. Recuperado a partir de http://www.portaldasmissoes.com.br/site/view/id/1450/tava-ou-jogo-do-osso.html

Puente, F. B., Visintini , G. F., Souza , R. A., \& Lorenzoni , C. C. (2019). Pitágoras e o Espantalho: Entre teoremas e equívocos. Anais da $8^{a}$ semana da Matemática (pp. 68 - 71). Vitória: Ifes - Vitória.

Radford, L. (2011). Cognição Matemática: História, antropologia e epistemologia. São Paulo: Livraria da Física.

Radford, L. Furinghetti, F., \& Katz, V. (2007). The topos of meaning or the encounter between past and present. Educational Studies in Mathematics, 66(2), 107-110.

Rogers, L. ; Pope, S. (2019). Tools and strategies for the history of mathematics in the classroom. In: Curtis, F. (Ed.) Proceedings of the British Society for Research into Learning Mathematics, 39 (2), June 2019.

Roque, T. (2012). História da Matemática: uma visão crítica, desfazendo mitos e lendas. Rio de Janeiro: Zahar.

Silva, C. M., \& Lorenzoni, C. C. (janeiro/dezembro de 2002). O velho conhecido Teorema de Pitágoras e suas demonstrações. História \& Educação Matemática, pp. 111-122.

Silva, V. (2016). Etnologia indígena: Revitalização da identidade cultural e linguística tupinikim do Espírito Santo. Dissertação de Mestrado, Programa de Pós-Graduação em Linguística, Instituto de Letras, Universidade de Brasília, Brasília.

Singh, S. (2013). Os Segredos Matemáticos dos Simpsons. Rio de Janeiro: Record.

Stewart, I. (2013). Dezessete equações que mudaram o mundo. Rio de Janeiro: Zahar. 
Viana, C. R. (1995). Matemática e Histórias: algumas relações e implicações pedagógicas. Dissertação de Mestrado, Faculdade de Educação - Universidade de São Paulo, São Paulo.

Vinha, M. (2010). Jogo de tabuleiro como prática educativa intercultural. In: B. S. Grando (Ed.), Jogos e culturas indígenas: possibilidades para a educação intercultural (p. 27). Cuiabá: EdUFMT.

Vygotski, L. S. (1995). Obras Escogidas: problemas del desarrollo de la psique. Madrid: Visor, 1995. T. III

Zaslavsky, C. (Maio de 1989). Integrating Math with the Study of Cultural Traditions. ISGEm Newsletter, 4 (2). Acesso em 01 de novembro de 2017, disponível em https://web.nmsu.edu/ pscott/isgem 42. htm

Autores

Ligia Arantes Sad

Doutora em Educação Matemática; (UNESP - Rio Claro, São Paulo - Brasil); Área de investigação: Educação; Linha de investigação: Educação Matemática e História da Matemática. Professora do Curso de Pós-Graduação de Educação em Ciências e Matemática (EDUCIMAT), IFES - Vila Velha e Professora da Coordenadoria de Matemática (COMAT) do Ifes- Vitória, ES/Brasil. Integrante do Grupo de pesquisas em História da Matemática e Saberes tradicionais (GHMat). Mais informações no Currículo Lattes: http://lattes.cnpq.br/1714140036102231. ORCID: https://orcid.org/0000-0002-2758-8380.

E-mail: ligia.sad@ifes.edu.br

Claudia Alessandra C. de Arujo Lorenzoni Doutora em Educação (PUC - Rio e Janeiro, RJ/Brasil; Área de investigação: Educação; Linha de investigação: Educação Matemática e História da Matemática. Professora da Coordenadoria de Matemática (COMAT) do IFES- Vitória/ES (Brasil). Integrante do Grupo de pesquisas em História da Matemática e Saberes tradicionais (GHMat). Mais informações no Currículo Lattes: http://Lattes.cnpq.br/8159438057989251. ORCID: https://orcid.org/00000002-7690-9646. E-mail: claudia.araujo@ifes.edu.br 